\title{
A Comparative Study on the Characteristics of Interactivity between Virtual Reality (VR) and Interactive Cinema
}

\author{
Da-Hee Jeong $^{1 *}$
}

\begin{abstract}
This paper compares VR cinema with interactive cinema from an interactive perspective to examine cinemas as a new medium. Rather than revealing the difference through this, the focus is on presenting a methodology that understands the cinema in a new environment that is now standing at the starting point. The development of video technology is changing not only the external elements of content but also the internal storytelling method, but the lack of killer content has always been pointed out as a problem compared to the remarkable development of technology. Therefore, it is necessary to specify the characteristics and types of interactions represented by VR (virtual reality) and new media represented by interactive media and to present directions. Therefore, the types and characteristics of interactions were compared with VR film < Help> produced in line with the new phenomenon and interactive film <Black Mirror: Bandersnatch>. Through this, we would like to present the meaning and value of the new film format from a media perspective.
\end{abstract}

Key Words: Virtual Reality, Interactivity, New media, Methodology, Interactive Cinema, VR Cinema.

\section{INTRODUCTION}

Interactive cinemas transform audiences from passive way to watch of traditional cinemas into active actors, giving them the characteristics of experience and participation. The development of media technology is leading everyday transformation and has a great impact on the art sector, and diversity of expression and reinvention has become possible. Today, technology, art, and media are organic and, as Marshall McLuhan said, "The only person who can face technology calmly is a true artist who can feel the change in five senses,"[1] there are more works that actively embrace the flow of society and use new media that reflect technology and culture [2].

Through this phenomenon, we would like to analyze the types and characteristics of interactions centered on the most popularly well-known VR and interactive cinemas produced by Google. In addition, the interactions between the two types of technically produced films show what features stand out.

Recently, research is drawing attention to the characteristics and types of interaction that are represented in movies using new media, which are represented by VR (Virtual Reality) and interactive media. In the era of new media, convergence between media leads to the spread of interaction with audiences, and rapid development and dissemination of video technology produced various new forms of video media such as VR cinemas, AR (Augmented Reality) games, interactive cinemas, and Internet personal broadcasting. In this paper, we want to summarize the characteristics through analysis and consideration of the format of the new cinema from the perspective of media theory.

\section{RELATED RESEARCH}

\subsection{Aspects of perspective change in film media theory}

The advent of the new media prompted the cinema to regain attention as a technology. In the $21^{\text {st }}$ century, there was a widespread view of the overall changes that the cinema went through as a direct result of digital technology. This is because as films were converted to digital, the aesthetic value of the cinema and the inherent of cinema culture lost their value and transformed into unfamiliar forms.

The current cinema, which has become the aggregate of digital technology, is technically a completely different medium from the cinema age but is still on the continuation

\footnotetext{
Manuscript received August 13, 2021; Revised September 08, 2021; Accepted September 22, 2021. (ID No. JMIS-21M-8-026)

Corresponding Author (*): Da-Hee Jeong, Dept. of Mass Communication, Pukyong National University, Busan, Republic of Korea, qwepoi754@ naver.com, +82-010-9222-2847

${ }^{1}$ Dept. of Mass Communication, Pukyong National University, Busan, Republic of Korea, qwepoi754@ naver.com
} 
of the cinema age. Francesco Casetti predicted, "The cinema is moving to a territory that was not his own, but he will still want to maintain his identity even if it is based on something completely different." With digital technology, movies have become a completely different medium, but they are still 'movies' [3].

Marshall McLuhan's media theory [4] states that new media create new art forms, define new art content, change the attitude of users, and expand art. Media-driven thinking suggests that the media creates new art forms and brings significant transformations in the art sector. However, the media has been regarded as secondary, a means and tool for expression and description. After the photo, the appearance of the movie took place from "art by media" where the medium was used as a tool or means to "art by media itself [5]."

From a media perspective of McLuhan, it is worth considering whether the advent of VR cinemas and interactive cinemas is a new art form brought by technology and whether it can be said to change the attitude of the users and expand the arts.

Thomas Elsaesser proposed the history of film as a media archeology. He argues that the identity of film as technology should no longer be addressed in the realm of film history, but in the realm of media history. In his latest book, "Film History as Media Archeology: Tracking Digital Cinema," he says that the task of film history today is essential to distinguish between movies before and after the transition to digital, but it should not be dichotomously described as "old." Thomas Elsaesser regarded the change as a result of a change in the nature of the technological medium of cinema, rather than the replacement of the old one by new technology, that is, the 'cinema has become invisible as a medium." Unlike the cinema age, the way of watching movie in these days has been absorbed into various multimedia media functions that can be easily carried around and accessible without space constraints [6].

\subsection{Comparison Between VR and Interactive Cinemas}

\subsubsection{VR cinema as a medium}

As interest in VR (Virtual Reality) has increased, related technologies have developed and marketability has increased in recent years. In addition, many examples of the combination of cinema and virtual reality (VR) are being captured. As for the core of VR, William Sherman said, "Interaction with the virtual world is the core of VR experience. In fact, it would not be VR if the virtual world display at least did not respond to the physical movement of the user [7]." Even if you watch the same movie, it is different to watch the movie at a movie theater with a screen all over the place and to watch it through HMD (HeadMount Display). The latter case reveals the difference from traditional films in that it gives a sense of existence and immersion. Some predict that VR maybe just a technological tool that is in vogue for a while, just as movies using 3D glasses, which producers had high expectations for, did not resonate much among real audiences. Nevertheless, experiments on VR cinemas are expected to continue to be tried [8].

\subsubsection{Interactive cinema as a medium}

Interactive cinemas are a type of game/film, also known as interactive cinema, interactive drama, and also called participatory films, interactive cinemas, and interactive videos in the film industry. It often refers to videos that use seamless full-motion videos in a way that has been frequently seen in adventure game genres in the past and enter specific buttons or commands in certain situations. The interactive cinema was recognized as a new genre of movie that allows audience to choose their own plots based on the Internet. However, there were no attractive elements such as narratives and poor quality compared with previous cinemas.

Director Shin Sera's <Kino Automart>, which can be seen as the first interactive film, was screened in a specially produced theater in Canada in 1967. The movie is suspended five times during the show, and each time, a live performer comes up to the stage and instructs the audience in the seat to vote by pressing the red and blue buttons on the seat to see how the next plot should proceed. The following storyline took place in a democratic way, which led to the majority's support as a result of the electronic vote. However, whichever button the audience pressed, the ending was the same. Due to the technical limitations of the time, various plot generation was limited too [9].

It was in the 2000 s that interest in interactive began in earnest in Korea. Director Cho Young-ho's "Young Hope's Day," dubbed Korea's first interactive cinema, was released on the Internet in 2001, recording 1 million views. Since then, the history of interactive cinemas has begun in Korea, including Choi Minhyuk's mobile interactive film < Touch Cinema - Retouching Love $>$ in 2012. With the advent of new media, "active interaction" between creators and audiences has become possible [10].

\section{INTERACTIVITY AND APPROACHES}

\subsection{Interaction on the Mediated Environment}

According to Lombard and Snyder (2001), interaction in a broad sense refers to all actions that a human does with an object, person, or entity under a given environment, and the media that provides the possibility of such action is interactive [11]. With the development of technology, not only PCs but also touchable smartphones and HMD headsets have become popular, media outlets have become a universal attribute in a broad sense. 
Interactive media means that communication between digital media and receptors is possible. Therefore, it is quite significant that control over interactive media information is transferred to the acceptor. In the case of the VR user, there is not much a 'spectator', but the 'actor'. So, interactivity is more personalized information and has the characteristics of active immersing the user into the experience of the mediated environment. There may also be different levels of interaction depending on the characteristics of the media and users.

According to Steuer [12], interactivity is a major factor in the construction of a virtual environment. Along with vividness, which means the technical ability to create a sensory-mediated environment, the concept is defined to the extent that users can influence the shape and content of the media within the mediated environment.

Murray classified the types of interactive media as Hypertext and Virtual Reality. A hypertext type is a form that provides participants with a set of choices open to new possibilities through selection at the junction of the story during the story's development process. It's like using elements of a game in a movie. On the other hand, virtual reality types allow participants to become actors or characters and to cause events or explore the fictional world in the virtual reality built by the media. This can be seen as a form of a game built in a cinematic environment, as opposed to hypertext types [13].

Akyazi explains that digital media, especially in terms of cyber-culture and virtual space implemented via the Internet, provides people with access to non-linear information, a sense of community affiliation, and face-toface communication. He also defines the concept of "interactive" as "behaving or affecting each other" and divides it into interactions between users-media, usersusers, and media-media [14].

The aforementioned researchers have different definitions of interaction. Thus, each researcher makes a different definition of interaction because of the different types of interaction. In addition, there are various media that cause interaction, and the purpose of use is different, so each researcher may have different rules for interaction. I have summarized the concepts of interactivity as shown in Table 1. However, some conceptual researchers of interactivity compiled here may be missing, so it is hard to say that all the interaction types are organized with this. That is why we have compiled the discussion of interactivity based on the approach within a limited framework.

\subsection{Categorization of interactions according to approach}

Usually, interactions occur through interfaces between media users and media that connect the two. Interactivity is that message forwarders and receivers can exchange roles. This is the process of exchanging, including the user's control of the content or form of mediated experience, as well as the response of the message recipient. See the table below for the categorization of various discussions on interactivity based on approaches. (Steuer, 1992; Lombard\&Snyder, 2001; Stapleton\&Hughes, 2007; Akyazi, 2005).

Table. 1. Categorize interactive definitions based on approach [15].

\begin{tabular}{|c|c|c|}
\hline Approach & Sources & Definition \\
\hline \multirow[t]{3}{*}{ Operability } & Steuer, 1992 & $\begin{array}{l}\text { Interactivity is about the } \\
\text { extent to which the user } \\
\text { can affect the mediated } \\
\text { environment and consists } \\
\text { of three lower dimensions: } \\
\text { speed, range, and } \\
\text { mapping. } \\
\text { - Speed: Regarding slow } \\
\text { or fast compared to reality. } \\
\text { - Range: How many } \\
\text { different contents can be } \\
\text { manipulated. } \\
\text { - Mapping: How much } \\
\text { user accessibility was } \\
\text { considered in order to have } \\
\text { a realistic interface. }\end{array}$ \\
\hline & $\begin{array}{l}\text { Lombard \& } \\
\text { Snyder- } \\
\text { Dutch, } 2001\end{array}$ & $\begin{array}{l}\text { The extent to which the } \\
\text { user influences the shape } \\
\text { and content of the } \\
\text { mediated environment. }\end{array}$ \\
\hline & $\begin{array}{c}\text { Stapleton \& } \\
\text { Hughes, } 2007\end{array}$ & $\begin{array}{l}\text { Depending on the device } \\
\text { used by the recipient, the } \\
\text { user type is divided into } \\
\text { 'Swimmers', 'Divers' with } \\
\text { HMD equipment, and } \\
\text { 'Waders' to see other } \\
\text { people's experiences. }\end{array}$ \\
\hline \multirow[t]{2}{*}{$\begin{array}{c}\text { Functional } \\
\text { aspects }\end{array}$} & Carey,1989 & $\begin{array}{l}\text { It refers to the degree of } \\
\text { human communication } \\
\text { through } \\
\text { telecommunication } \\
\text { channels and the degree of } \\
\text { interaction between people } \\
\text { and media who can } \\
\text { exchange personal } \\
\text { information such as } \\
\text { electronic banking. }\end{array}$ \\
\hline & Laurel, 1990 & $\begin{array}{l}\text { Divided by frequency, } \\
\text { range, and degree of } \\
\text { significance, focusing on } \\
\text { functional aspects of the } \\
\text { media. }\end{array}$ \\
\hline $\begin{array}{l}\text { Psychologic } \\
\text { al and } \\
\text { perceptual } \\
\text { aspects }\end{array}$ & Tassel, 1994 & $\begin{array}{l}\text { Categorized based on } \\
\text { users' communication } \\
\text { needs (cybernetics } \\
\text { /homostatic) }\end{array}$ \\
\hline
\end{tabular}


A Study on the Interaction between Virtual Reality (VR) and Interactive Film Media Environment and Approach

\begin{tabular}{|c|c|c|}
\hline & $\begin{array}{c}\text { Newhagen et } \\
\text { al, } 1996\end{array}$ & $\begin{array}{l}\text { Based on the degree of } \\
\text { psychological sensation } \\
\text { that detects the interaction } \\
\text { between the message } \\
\text { sender and receiver. }\end{array}$ \\
\hline & Strain, 1997 & $\begin{array}{l}\text { Divide into } 3 \text { levels based } \\
\text { on user needs and } \\
\text { technical proficiency }\end{array}$ \\
\hline & $\begin{array}{c}\text { Ha\&James, } \\
1998\end{array}$ & $\begin{array}{l}\text { Divided by degree of } \\
\text { reaction between the } \\
\text { communicator and user. }\end{array}$ \\
\hline & $\begin{array}{c}\text { Kiousis, } \\
1999\end{array}$ & $\begin{array}{l}\text { Distinguished by the } \\
\text { level of users' ability to } \\
\text { increase awareness of } \\
\text { telepresence by } \\
\text { experiencing situations of } \\
\text { interpersonal } \\
\text { communication. }\end{array}$ \\
\hline & $W u, 2000$ & $\begin{array}{l}\text { Divided by perceived } \\
\text { control, perceived } \\
\text { response, perceived } \\
\text { personalization. }\end{array}$ \\
\hline & $\begin{array}{c}\text { Coyle\& Thor } \\
\text { son, } 2001\end{array}$ & $\begin{array}{l}\text { Depending on the degree } \\
\text { of three aspects of } \\
\text { mapping, speed, and user } \\
\text { control, focusing on } \\
\text { perceptual rather than } \\
\text { functional aspects of } \\
\text { interaction. }\end{array}$ \\
\hline & $\begin{array}{c}\text { McMillan\& } \\
\text { Hwang, } \\
2002\end{array}$ & $\begin{array}{l}\text { The effects of media } \\
\text { interaction are related to } \\
\text { the direction, user control, } \\
\text { and perceived interaction } \\
\text { over time of users' } \\
\text { communication. }\end{array}$ \\
\hline & $\begin{array}{l}\text { Sohn\&Lee, } \\
2005\end{array}$ & $\begin{array}{l}\text { Users' use of text is more } \\
\text { affected by cognitive } \\
\text { needs such as } \\
\text { psychological factors } \\
\text { (control, responsiveness, } \\
\text { and interaction } \\
\text { convenience) than social } \\
\text { factors. }\end{array}$ \\
\hline \multirow{2}{*}{$\begin{array}{l}\text { Combined } \\
\text { aspects of } \\
\text { process, } \\
\text { characterist } \\
\text { ics, and } \\
\text { perception }\end{array}$} & $\begin{array}{c}\text { Rafaeli, } \\
1988\end{array}$ & $\begin{array}{l}\text { process-oriented concept } \\
\text { : Sequential relationships } \\
\text { or relatedness between } \\
\text { messages }\end{array}$ \\
\hline & Heeter, 1989 & $\begin{array}{l}\text { Includes media } \\
\text { functionality, selectability, } \\
\text { user effort and response, } \\
\text { monitoring the use of } \\
\text { information, ease of } \\
\text { adding information, and } \\
\text { facilitation of interpersonal }\end{array}$ \\
\hline
\end{tabular}

\begin{tabular}{|l|l|l|}
\hline & communication. \\
\cline { 2 - 3 } & Akyazi, 2005 & $\begin{array}{l}\text { Non-linear information } \\
\text { accessibility, a sense of } \\
\text { community affiliation, and } \\
\text { a sense face-to-face } \\
\text { communication, divided } \\
\text { into user-media, user-user- } \\
\text { media interactions. }\end{array}$ \\
\hline
\end{tabular}

\section{INTERACTIVE EXPERIENCE ANALYSIS OF FILM EXAMPLES}

An important point for interactive experience analysis in interactive cinema works is that users show different empirical contexts even in the same environment. Users experience different depths of interaction due to the way they choose to participate based on their personal behavior.

According to Stapleton and Hughes [16], user-delimited criteria can be divided into three categories: The first is Swimmers. Instead of wearing equipment such as HMD, it is a type of user who only looks at flat screens. The second is 'Divers'. It is a type of user who actively jumps into HMD while wearing it. The third is 'Waders', a type of user who is satisfied to see what others are experiencing [16]. This categorization of types between Stapleton and Hughes is applicable to recipients consuming interactive media. The following examples of works demonstrate what level of interactive experience the Users had.

\subsection{VR Film $<$ Help $>$}

The live-action short VR film $<$ Help $>$ (2016), directed by Justin Lin, was introduced on Google. The film $\langle$ Help $>$ is a short five-minute movie about alien life invading the Earth and destroying Los Angeles in the U.S. 360-degree movies are different from traditional cinemas. Because the audience doesn't know where to look in the movie's space, they have to shoot literally everything that exists.

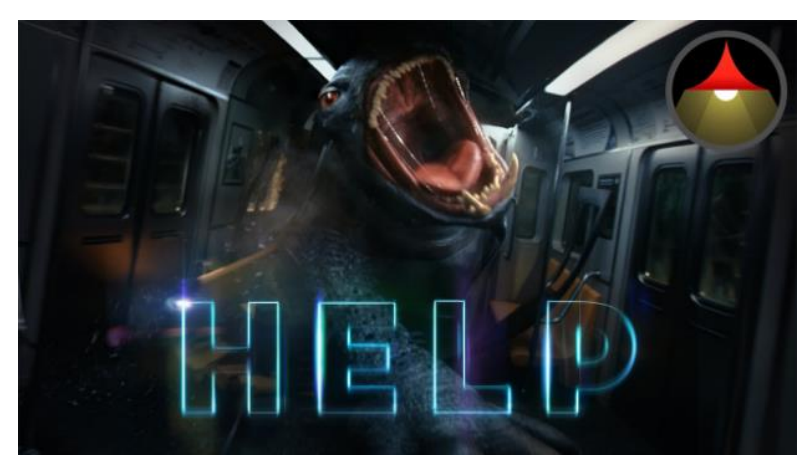

Fig. 1. The live-action short VR film $<$ Help $>$ (2016). 
The 360-degree imaging technique used in the cinema is characterized by allowing users to adjust the angle they want to see various spaces and scenes. Therefore, unlike previous movies, you can freely see the scenes you want to see, making you feel as if you are the main character in the movie [17].

There are three ways to enjoy $<$ Help $>$. The first is how to use the mouse of a PC to change the view and appreciate it. Second, you can watch movies by touching or moving your smartphone directly using a mobile. In this case, space is needed because you have to hold a cell phone and move it from side to side. Lastly, there is a way to appreciate using an HMD headset. Watching movies using HMD headsets has the advantage of being able to feel a sense of space rather than holding a smartphone. However, the disadvantage is that depending on the performance of the device, the quality, and immersion of the content may be interrupted.

According to the Stapleton-Hughes method [16], audiences who watch through PCs and smartphones can be seen as Swimmers. And those who watch through HMD headsets can be divers. However, PC and smartphone viewers appear in a mix of characteristics of Swimmers and Divers because they are actively interacting with each other in terms of manipulation.

\subsection{Interactive Cinema <Black Mirror : Bandersnatch>}

The interactive film <Black Mirror: Bandersnatch> (2018), released in December 2018 by streaming service provider Netflix, is a special episode of the TV series <Black Mirror>(2013-). The cinema featured multiple-path narratives that can be seen in games. While watching the movie, the option to choose the path as a game came up, giving the audience the fun of changing the direction of the story [18].

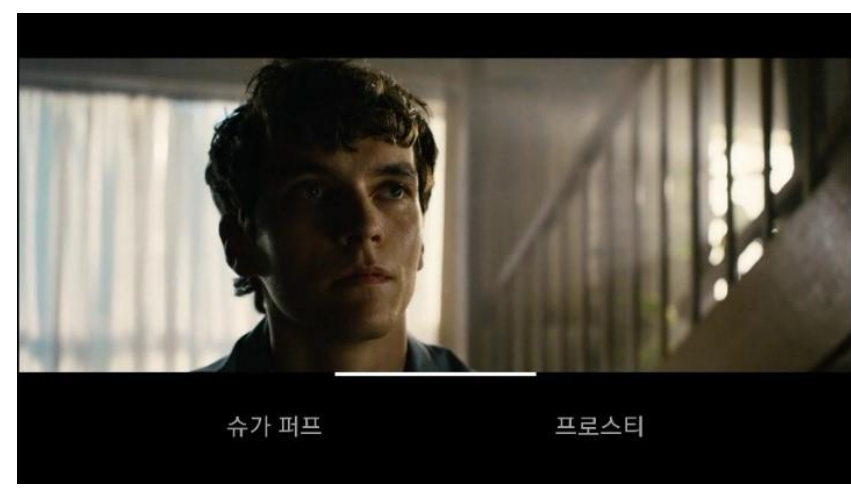

Fig. 2. The interactive film: $<$ Black Mirror: Bandersnatch $>(2018)$.

Strain (1997) stated that interactivity enables active choices and decisions about what content, when, and how it can be communicated to users under multimedia circumstances. In addition, three levels of interaction exist depending on the user's needs and technical proficiency. The first stage is the level at which the media allows users to access content, and the second stage is the level at which users can choose their own way of behaving. Finally, the third stage is the implementation of the highest level of interaction. Users can become authors who can freely change content. As a result, it refers to the steps in which the content that each user experiences can vary [19].

According to Park Ju-ran (2015), a writer or designer starts work in the form of a traditional plot, but it is the player who completes the plot in detail, and this area is called the player's hierarchy [20]. Interactive cinemas are offered to acceptors aiming at "movie appreciation experience" so that they can follow traditional plots at the designer level and experience different paths depending on participation at the player level. In that respect, the interactive film <Black Mirror: Bandersnatch> can be seen as content that properly implements the three stages presented by Strain based on the platform called Netflix.

Adriano D'aloia said, "The arguments that, a bit provocatively, I have tried to make here are not meant to advance an aversion to interactivity founded on the simplistic and reductive idea that Bandersnatch is not a film because it is too interactive, and is not a video game because it is not interactive enough [21]." As he said, it is difficult to say that this work is a perfect interactive cinema. Interactive Cinema is relatively less focused and immersed than traditional cinema. However, among the transitional works, it is thought to be a representative work that informed the public of the interactive cinema through a streaming.

\section{DISCUSSION}

\subsection{Shifted paradigm in film grammar}

The development of film is closely related to the development of film technology. Cinema has changed from silent films to sound films, from black-and-white to color movies, and widescreen and 3D movies have appeared. As a result, the film has developed toward a faithful and perfect reproduction of reality. Then, we can ask how VR will change the Cinema, why it is drawing attention as a new era of video media and content, and how it will develop in the future. It's hard to answer these questions in a word, but it's clear that the changes derived from VR are on a completely different level from the changes made by technology in previous conventional 2D movies.

VR cinema are clearly different from traditional 2D 
movies. $360^{\circ}$ shooting will extend the non-visible area to the visible area, maximize the indirect experience in emotional identification through empathy for characters, and the audience's dramatic intervention will expand to create an independent audience. At the center of this change is the freedom of the VR cinema to the audience, which is the first time the audience has acquired since the birth of the movie. The subjectivity of this gaze sub verses movie language and movie grammar, which only conveyed selected views.

A free point of view derived from the $360^{\circ}$ shooting of VR requires a paradigm shift in film grammar. Unlike previous movies, Shin Hong-joo said, "There are problems such as lack of tension between inside and outside the frame, cracks in space and time due to interaction, and control of timing [22]." Technically, frames do not exist in $360^{\circ}$ images. This means the dismantling of "Shot," the basic unit of film language. In other words, in VR cinema, storytelling and scenario writing based on the language and grammar of the film cannot exert its power. Since the birth of the movie, the audience has been a passive observer. However, VR cinemas now require the audience to be an independent participant who decides the structure of the movie. Therefore, in VR cinemas, only the description of scenes, not images in short or cut, becomes useful.

Ultimately, VR cinema want a change from classic cinema content that unilaterally accepts pre-written stories to "interactive" content that is completed with audiences. The audiences are also showing a willingness to participate in VR cinema actively and independently, which will not be stopped. Through games such as Overwatch, users are already familiar with the illusion that they are actively participating in the environment. VR cinema will draw audiences to feel more real and provide a realistic environment than games. This is a difference from traditional 2D movies, and it will be an advantage of VR cinema and a direction for future VR cinema.

\subsection{Interaction between audiences}

The current method of accepting the medium of film is determined by the way the theater is screened and the way the movie is viewed. VR has only a completely personal viewing method called HMD and an individual exchange of media in the screening and viewing method, in which there is emotional empathy and emotional exchange with people in the same space while watching the same movie in the theater. Therefore, it is necessary to think about the storytelling method so that the individual viewing method and environment of the new technology and media era of VR movies can lead to the desire for emotional exchange, empathy, communication, and communication with others [23]-[25].
We can reconsider the question Martin Heidegger asked about technology. What is this technology for? Where is the era of new technology heading? So, how does new media intervene in communication? Did this enhance the intimacy that communication aims for? In this question, the more we rely on new media to communicate, the deeper the sense of isolation and alienation of modern people. This is because communication by new media has little to do with the promotion of intimacy.

In the theater, there may be empathy and emotional exchange with people in the same space while watching the same movie. However, VR takes a completely personal viewing method using HMD. So there is only exchange between the media and individuals. We think that this evaluation is limited to a device called HMD.

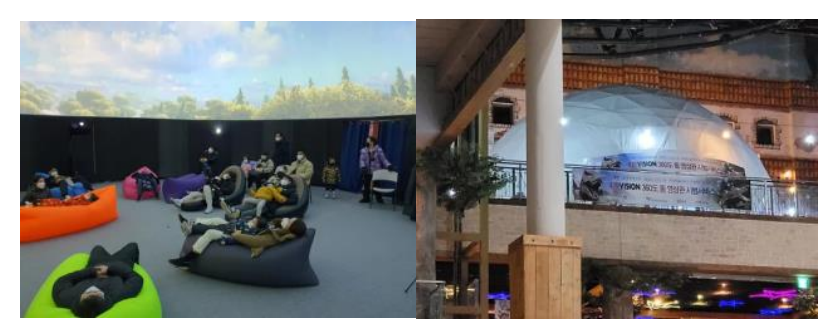

Fig. 3. Hyper Dome Video Studio in Gumi.

In 2016, 4 Division Co., Ltd., a Korean company, developed five 360-degree dome videos and an operating platform exclusively for virtual reality (VR) dome video theaters. The video hall is 12 meters in diameter and 7.5 meters in height, and about 15 people can watch it at the same time. The Hyper Dome Video Center, located in Gumi City, introduced a realistic video that allows users to watch VR (virtual reality) videos without HMD for the first time in Asia [26].

In 2017, the following year, the company established a "Hyper Dome Video Center Barrier Free Mobile System," an auxiliary subtitle synchronization service based on sound recognition, and held a demonstration. Through these examples, it is possible to find the possibility that new media can aim not only for the public but also for communication with the disabled.

The Hyper Dome Video Studio, which combines VR technology with traditional viewing methods, provided a new visual beauty to the audience. These technological advances could serve as a stepping stone for answering Heidegger's questions about how new media is involved in communication.

\section{CONCLUSION}

According to Marshall McLuhan's media theory, the Internet and digital media have created a new art form, VR 
and interactive media. This is not a regression of traditional art cinemas, but an expansion or evolution of art. Regarding the relationship between VR technology and cinematic aesthetics, Moon Won-Reep argued that VR is ironically a distraction from art cinema [27].

However, in this paper, I think VR cinemas can also enter the realm of art. VR Cinemas have expanded the range of mise-en-scenes, and it is hard to say that they are completely out of line with the existing art grammar of cinemas. Because it still follows the traditional method of production. The shadow of "death" in the film industry at the time of the film's transition to digital has now entered a different phase.

Due to the influence of Corona 19, the demand for realtime content services such as VR and AR has also increased with the increase in social distancing and non-face-to-face activities around the world, especially indoor activities such as homes and offices. Realistic content markets such as AR and VR are considered to have high marketability and growth potential, based on the 4th Industrial Revolution [28].

As Thomas Elsaesser said, this change by new technology is not a replacement for old things, it's just those movies that have undergone technological changes. Therefore, contrary to Moon Won-Reep's argument, the cinematic arts appreciated from a media perspective do not diverge but have the meaning of transformation as a new medium.

So far, it has been difficult to consider such things as artistic discourse or ideas while watching interactive or VR cinemas. In this regard, both interactive and VR cinemas can find common limitations in the lack of internal factors in content.

Interactive cinemas appeared in the process of the change. Generally, speaking, all movies are interactive. However, the reason why interactive cinemas are largely distinguished from traditional cinemas is that they are completed through physical interaction between the interface and the audience based on digital technology.

This paper compares VR cinemas with interactive cinemas from an interactive perspective to look at movies as a new medium. Rather than revealing the difference through this, the focus is on presenting a methodology that understands the cinema in a new environment that is now standing at the starting point.

Therefore, interactive cinemas require a different paradigm from conventional cinemas in all areas, ranging from production, acceptance, and distribution to narrative composition. However, the small number of interactive cinemas currently being released is not enough. Traditional cinemas are difficult to compare because they already have a broad spectrum of discussion [29].
In the future, you will not just watch the movie but actually experience it. But it's too early to jump to conclusions. No matter how ingenious the technology is, if the content does not follow, it will be just a tool to convey the story well. But as mentioned above, VR technology itself has the potential to grow economically on the outside of the content, and the internal elements of the content storytelling are to keep changing. So, the cinema, which will be produced based on virtual reality and digital imaging technology, is expected to be valued as a new form of media art.

\section{REFERENCES}

[1] Marshall McLuhan, Understanding the Media, Communication Books, pp.41, 1997.

[2] Hae-Young Yoo, "A Study on the Interaction Types and Characteristics of New Media Art," Korea Digital Design Council, vol. 15, no. 2, pp.491. 2015.(Korean Paper)

[3] Chan-Cheol Jeong, "The Technological Turn in the Historiography of Cinema: Techno-Cinema and Techno-Cinema-Art," Korean Cinema association, vol.72, pp.12. 2017. (Korean Paper)

[4] Marshall McLuhan, Understanding Media: The Extension of Man, Communication Books, 2011.

[5] Hye-Ryun Shim, "Art and Media and Möbius Band," Philosophy, Reading Art. Academy of Philosophy, Dongnok, pp.144-159, 2006. (Korean Paper)

[6] Thomas Elsaesser, "Film History as Media Archaeology: Tracking Digital Cinema," Amsterdam: Amsterdam University Press, pp.17-18. 2016. q

[7] William R. Sherman, "Understanding Virtual Reality: Interacting with the Virtual World,"Morgan Kaufmann, pp. 283. 2002.

[8] Korea Broadcasting and Telecommunication Promotion Agency, "The Latest Case Analysis of Virtual Reality (VR) Film`s," 2018 KCA Media Issue \& Trend, Trend Report 01, pp. 12, 2018.

[9] J. K. Jin, “video game or interactive cinema," Mar. 2008, http://www.cine21.com/news/view/?mag_id=50652.

[10] Da-Hee Jeong, "Possibilities and Limitations of Interactive Media: Focusing on interactive documentary," M.S. thesis, Stroytelling, Dong-Eui University, Busan, Korea, 2018.

[11] Lombard, M \& Snyder-Duch, "Interactive advertising and presence: A framework," Journal of Interactive Advertising, vol. 1, no. 2, pp. 56-65, 01 Jul 2013.

[12] Jonathan Steuer, "Defining virtual reality: Dimensions determining telepresence," Journal of Communication, vol. 42, no. 4, pp. 73-93, 1992.

[13] Janet H. Murray, Hamlet on the Holodeck: The Future 
of Narrative in Cyberspace, New York, The Free Press, pp. 126-153. 1997.

[14] E. Akyazi, "Cyber-culture and interactivity," in Proceedings of $3 r d$ international symposiums of interactive media design (ISIMD), Istanbul, pp. 5-7, Janu. 2005.

[15] Sung-Bok Park, "Digital Interactivity," Hanyang University Graduate School of Media and Information, pp. 4-5. 2016.

[16] Stapleton, Christopher \& Hughes, Charles, "Mixed Reality and Experiential Movie Trailers: Combining Emotions and Immersion to Innovate Entertainment Marketing," IEEE Computer Graphics and Applications, vol.25, no. 05, pp. 23-27, 2005.

[17] https://vimeo.com/129240342

[18] Myung-Hee Nam, "Analysis of The Multiple Path Narratives on Black Mirror: Bandersnatch," The Journal of Image and Cultural Contents (JICC), vol. 17, pp. 151-172, 2019.

[19] Sun-Ju Hong, Tae-Yong Kim, "Demystifying the Communication Effects of Interactive Drama: Focused on the Mediating Role of Telepresence," Journal of Cyber communication Academic Society, vol. 27, no. 1, pp. 255-292, 2010.

[20] Ju-Ran Park, "A Study on The Narrative Forms of Video Games and Digital narrative Structure Characteristics," M.S. thesis, Department of Arts, Hanyang University, Seoul, Korea, pp. 1-92, 2015.

[21] Adriano D'aloia, Against Interactivity, "Phenomenological Notes on Black Mirror: Bandersnatch," International Journal of TV Serial Narratives, vol. 5, no. 2, pp. 21-32, Winter 2020.

[22] H. J. Shin, "An Examination of Point of View in VR Contents," in Proceedings of Conference on The Animation Society of Korea, vol. 2016, no. 6, pp. 183188, June 2016.

[23] Byoung-Won Jeon, Min-Chol Cha, "VR \& Changes in Cinematic Storytelling Focusing on film composition unit, montage, space, mise-en-scene and perspective," Journal of Korea Multimedia Society, vol. 21, no. 8, pp. 991-1001, Aug. 2018.

[24] Tae-Jung Kim, Jun-Ho Huh, Jin-Mo Kim, "Bidirectional education contents using VR equipments and augmented reality," Multimedia Tools and Applications, Springer, vol. 77, no. 22, pp. 3008930104, June 2018.

[25] Sang-Guk Lim, Se-Hoon Jung, and Jun-Ho Huh, "Visual algorithm of VR e-sports for online health care," Healthcare, vol. 9, no. 7, pp. 1-29, 2021.

[26] 4D Vision, "360VR Dome Video Studio Open!," https://www.4dvision.co.kr/single-,post/360vr-\%EB\% 8F\%94-\%EC\%98\%81\%ЕC\%83\%81\%ЕA\%B4\%80-\%

\section{EC\%98\%A4\%ED\%94\%88}

[27] Won-Leep Moon, "VR and Cinema," Dongguk University Research Center for Image, Cineforum, vol. 22, pp. 351-375, 2015.

[28] Korea Institute for Industrial Economics \& Trade (KIET), Future Strategic Industry Brief, vol. 12, pp. 3540, April 2020.

[29] Woon-Gyoung Ghe, "Space of the Interactive FilmVirtual Space, Cyberspace, Remediation Space," Contemporary Cinema Research Institute, vol. 35, pp. 10, 2019.

\section{Author}

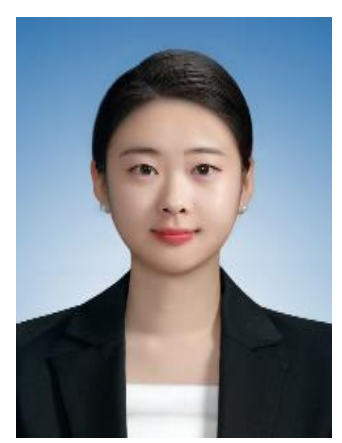

Da-Hee Jeong was born in Busan, Republic of Korea. In Feb. 2015, she graduated from Dong-Eui University at Busan, Department of Film Study in Korea, and received her master's degree in storytelling. She participated in a VR cinema production workshop organized by the Busan Center for Creative Economy and Innovation in 2016. And she took the opportunity to attend Auckland School of Technology in New Zealand as a scholarship student for the project. In addition, he acquired the world's best motion capture, animation, and VR technology owned by Oakland College of Technology.

She is preparing for a doctorate in mass communication at Pukyong National University. Currently, she works for the company "gematek". This company is conducting research on the data construction business for artificial intelligence (AI) learning. Her research interests are New media (Interactive media, VR, etc.) and Big data. 